\title{
OS ÍNDIOS E NÓS: UMA REVISITAÇÃO
}

RAFAEL SEVERIANO ${ }^{1}$

UFRJ/UFPA

\section{RESENHA}

SEEGER, Anthony. Os índios e nós: estudos sobre sociedades tribais brasileiras. Rio de Janeiro: Campus, 1980. 181 p.

Os índios e nós: estudos sobre sociedades tribais brasileiras é a reunião de trabalhos escritos por Anthony Seeger, até aquele momento (1980), sobre os Suyá (Kisêdjê) e outras sociedades indígenas das terras baixa da América do Sul (TBAS).

Passados já quase 36 anos da publicação do livro, sua revisitação torna-se altamente relevante, pois as questões ali levantadas e discutidas encontram-se atuais e pertinentes tanto para a Etnomusicologia quanto para a Antropologia, e deve continuar inspirando pesquisadores destas áreas. Diversos dos pontos ali discutidos encontram ressonância no recém-lançado Por que cantam os Kisêdjê: uma antropologia musical de um povo amazônico (2015), tradução de Why Suyá Sing: A Musical Anthropology of na Amazonian People (2004 [1 987]).

O livro está dividido em sete capítulos, sete textos publicados em momentos e periódicos diversos que aqui foram reunidos para formar esta obra. Cada capítulo possui uma breve apresentação ao tema que

\footnotetext{
${ }^{1}$ Mestre em Artes, com ênfase em Etnomusicologia, pela Universidade Federal do Pará (UFPA). Bacharel em Música - Trombone - pela Universidade Federal do Rio de Janeiro (UFRJ). E-mail: rafael_severiano@yahoo.com.br.
} 
será trabalhado, bem como informações da publicação do texto.

Figura 1 - Capa do livro.

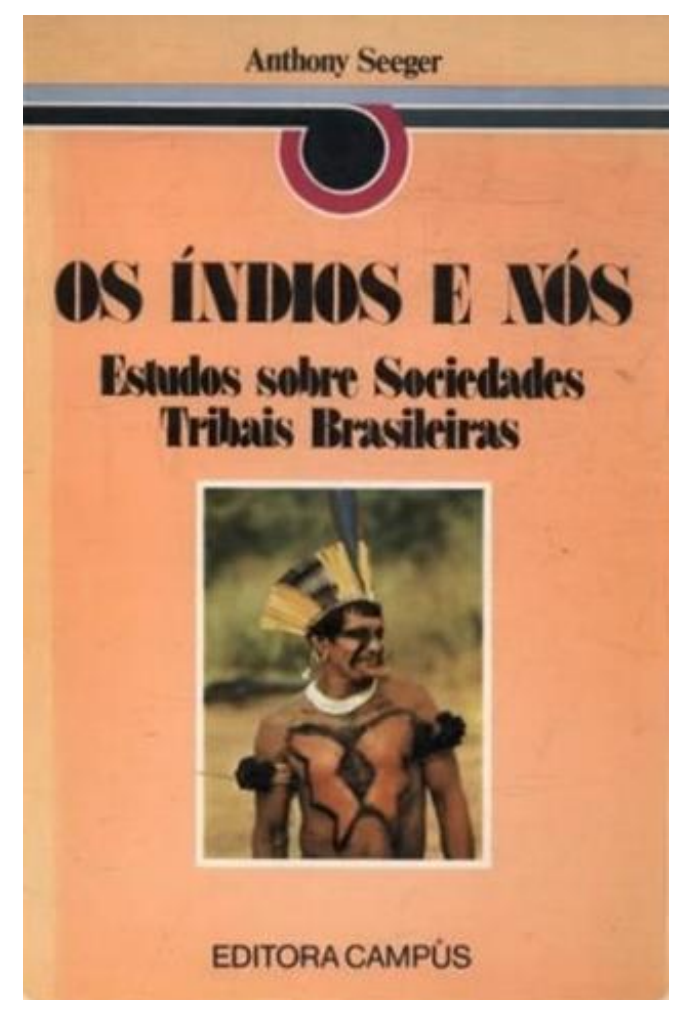

Fonte: Seeger (1980).

$\mathrm{Na}$ apresentação geral do livro, Seeger diz que o estudo das sociedades indígenas, em suas especificidades e singularidades, deveria nos inspirar a reconsiderarmos nossas relações com as mesmas, e em especial as políticas indigenistas e as dificuldades pelas quais os membros de tais sociedades estavam passando e lutando contra. Para Seeger, a questão não seria tanto avaliar estas sociedades em relação a nós mesmos, mas considerá-las, e a nós mesmos, como partes de uma grande variedade de soluções diferentes para problemas semelhantes. Tal consideração continua extremamente atual! Seeger finaliza a apresentação geral com uma breve apresentação dos Kisêdjê, a fim de contextualizar o leitor para os textos que se seguirão.

Pesquisa de campo: uma criança no mundo é o capítulo 1 do livro, onde Seeger procura responder algumas questões do trabalho de campo tendo como base seu trabalho entre os Kisêdjê. $\mathrm{O}$ autor aponta que o 
"material etnográfico sobre o qual a Antropologia trabalha é quase sempre resultado da atividade singular do pesquisador no campo, num momento específico de sua trajetória pessoal e teórica" (SEEGER, 1980, p. 25).

Seeger declara não ter utilizado entrevistas estruturadas, apenas uma lista de perguntas que servia de base, e que utilizava gravador apenas para narrativas, músicas e descrições de cerimonias que não presenciara. Ao invés de consultar alguns informantes, utilizou todos os membros da aldeia. Havia, ainda, os "especialistas" de certos domínios culturais, que forneciam maiores informações e mais detalhadas.

Seeger encerra seu trabalho de campo não por acreditar saber tudo, mas o suficiente sobre as áreas que lhe interessavam. Sua experiência pessoal com os Kisêdjê, ao invés de ser um obstáculo, o auxiliou a coletar dados mais significativos.

O significado dos ornamentos corporais é o capítulo 2. Os Kisêdjê entendem-se como um grupo diferente dos demais por usarem discos nos lábios e nas orelhas e por cantarem em estilo particular. Nenhum outro grupo teria esses três atributos e por isso nenhum grupo seria completamente humano. Assim, na sociedade kisêdjê, a fala e a audição são complementares. Para Seeger, os discos labiais ou auriculares estariam associados à importância cultural atribuída à audição e à fala. Usando as categorias kisêdjê de percepção e expressão, e o comportamento moral como base para a análise, Seeger conclui que, acima de tudo, os ornamentos corporais tornam conceitos intangíveis em conceitos tangíveis e visíveis.

Como observado por Seeger, os Kisêdjê não possuíam outros instrumentos além dos chocalhos, a música kisêdjê sendo exclusivamente vocal. Certas formas estavam intimamente relacionadas com formas de falar. "Cantar é o máximo da expressão oral, tanto individual como coletivamente" (SEEGER, 1980, p. 48). Por se tratar de uma reunião de textos, estas considerações sobre a música kisêdjê aparecem mais de uma vez.

Os velhos nas sociedades tribais é o capítulo 3. Ao estudar o status dos velhos nas sociedades indígenas das TBAS, Seeger declara ter ficado surpreso com o pouco que sabia e publicava-se sobre o assunto. Passados quase 26 anos desta constatação, me parece que o assunto 
ainda carece de mais pesquisas.

Os Kisêdjê, como todos os Jê setentrionais, possuem sistemas de classe de idade, onde as pessoas são agrupadas e classificadas a partir de sua posição no ciclo da vida: tamanho da criança, status conjugal e números de filhos, por exemplo. Tais classes são hierárquicas; logo, os mais velhos possuem maior prestígio que os mais jovens.

A última fase da vida de um kisêdjê é denominada wikényi, tanto para homens como para mulheres; compreende a fase das pessoas que têm muitos netos. Os wikényi participam das práticas musicais com gritos específicos: gritos curtos, ascendentes, em glissando e em falsete alto.

Espera-se que os wikényi como grupo tenham determinado comportamento, bastante oposto aquele que o kisêdjê normal, moralmente correto, deve ter. Os wikényi são altamente respeitados pelo seu saber cerimonial, eles são necessários "para a execução correta e, em razão de seu saber, adquirem prestígio" (SEEGER, 1980, p. 72). Seeger traça um panorama dos velhos em outras sociedades jê, apontando para os papéis de mediadores políticos e supervisores das atividades cerimonias que estes exercem.

O que podemos aprender quando eles cantam? Gêneros vocais do Brasil central é o capítulo 4. Seeger apontou que, até aquele momento, a música era uma área de pesquisa negligenciada. Embora esse cenário venha mudando, a música dessas sociedades continua sendo pouco conhecida, analisada e compreendida.

A estética da música kisêdjê envolve mais do que a simples avaliação dos sons produzidos pelos cantores - o que parece ser comum nas sociedades das TBAS. Seeger assinala que fazer música é fundamental nas cerimonias kisêdjê; assim, a análise da música é fundamental para compreender as sociedades do Brasil central. A noção dos Kisêdjê de música "bela" é quando tudo na performance sai como deveria.

Para Seeger, a música

é uma forma específica de comunicação. Suas características não-verbais fazem dela um veículo privilegiado para transmitir valores e éthos que são mais facilmente "musicados" que verbalizados. Estes são comunicados não somente através dos sons, mas 
também dos movimentos dos intérpretes, do tempo, do local e das condições em que são executados (SEEGER, 1980, p. 84).

Esta concepção da música para além dos sons é fundamental na proposta de performance musical de Seeger.

Se fazer música seria mais do que produzir sons estruturados, a melhor abordagem dos eventos musicais, segundo Seeger, seria

\begin{abstract}
analisar o acontecimento total investigando as questões jornalísticas de "o que", "onde", "como", "quando", "por quem", "para quem", "por quê", etc. As respostas a essas questões fornecerão uma etnografia da execução musical com que qualquer análise deveria começar (SEEGER, 1980, p. 86).
\end{abstract}

Seeger apresenta dois gêneros de canções que são contrastantes, a akia e o ngere. Dentre as características principais da akia apontadas por Seeger, destaco que são cantadas somente pelos homens individualmente - ainda que indivíduos possam cantar simultaneamente akia diferentes -, e cantadas o mais agudo e o mais forte possível; já a ngere é cantada em grupo e em uníssono, grave e em volume moderado com os indivíduos tentando combinar suas vozes; às vezes as mulheres cantam como grupo ou com os homens.

Para Seeger, a estrutura da música kisêdjê não é um reflexo da sociedade - como alguns dos pressupostos etnomusicológicos poderiam sugerir -, mas é parte da criação e contínua recriação das características duais desta sociedade; a estrutura dual da música é fundamental, não reflexiva. A música desempenha papel importante "na criação e na vida da própria sociedade: sua criação musical e sua vivência musical" (SEEGER, 1980, p. 103). Aqui, temos uma contribuição singular de Seeger, acreditamos que tal noção possa ser aplicada à música de todo e qualquer povo.

As akia e muitos ngere são aprendidos de mamíferos, peixes, pássaros, abelhas e plantas, e ensinados aos homens da aldeia. No entanto, os Kisêdjê não davam muita importância ao processo de composição das ngere, porque é um animal, planta ou abelha que está cantando a canção; o compositor seria um mediador que aprende a canção e então a ensina ao resto dos homens. 
A noção kisêdjê de música "bela" é quando tudo na performance sai como deveria. De acordo com Seeger, a análise da música das sociedades indígenas das TBAS pode fornecer indicações importantes na tentativa de compreendê-las, mas, para isso, seria "necessário analisar o evento musical total e a forma como a música se insere no quadro social e cosmológico mais amplo" (SEEGER, 1980, p. 103).

"Nossa suposição de que a música é uma 'arte', uma atividade antes de tudo estética e além disso incidental, fez com que não entendêssemos a música" (SEEGER, 1980, p. 103) das TBAS. "Para essas sociedades, a música é parte fundamental da vida social, não somente uma de suas opções" (SEEGER, 1980, p. 104). Assim, a análise da música pode nos fornecer indicações importantes para a compreensão dessas sociedades.

Substância física e saber: dualismo na liderança Kisêdjê é o capítulo 5. Segundo Seeger, de todas as características das sociedades indígenas no Brasil, a organização política é uma das mais difíceis de serem compreendidas por nós, ocidentais. Existem dois tipos de líder entre os Kisêdjê: os líderes políticos (mẽropakandé) e os líderes cerimoniais (mẽrokinkandé).

No geral, a posição de mẽropakandé é herdada patrilinearmente. O mẽropakandé não possui poder para comandar, ele deve constantemente aumentar o apoio que tem de sua facção e do resto da aldeia. Ele deve influenciar os indivíduos a seguirem seu conselho; se não consegue, o grupo ignora seu conselho.

Já para a posição de mẽrokinkandé não existe uma regra fixa, mas depende de interesse, talento musical e de ter perdido o espírito. Os homens sem espírito tiveram seus espíritos retirados de seus corpos e escondidos com espécies animais ou vegetais. Credita-se à feitiçaria esse perder o espírito. Os homens sem espírito ouvem e compreendem a fala e as canções da espécie com quem seu espírito passou a residir. Muitas das cerimônias kisêdjê exigem que cada homem cante uma nova canção, e os homens sem espírito ensinam essas canções aos demais homens.

Os dois papéis são necessários e complementares, e ambos são mediadores: os mẽropakandé entre os homens e os mẽrokinkandé entre os homens e os animais. "A sociedade é perpetuada por essa contínua 
transferência de canções dos animais para os homens, porque novas canções são exigidas para que as cerimônias se realizem corretamente" (SEEGER, 1980, p. 124).

No capítulo 6, Corporação e corporalidade: ideologias de concepção e descendência, Seeger apresenta aspectos do parentesco dos Kisêdjê. Para Seeger, uma análise satisfatória das sociedades indígenas das TBAS exigiria "cuidadosa atenção às complexas redes de relações que são tão onipresentes, bem como às outras formas de organização como as classes de idade, as relações de nominação e os grupos cerimoniais" (SEEGER, 1980, p. 125). "As sociedades das terras baixas da América do Sul podem chamar nossa atenção para as características de outras sociedades antes não percebidas e aprimorar nossa compreensão delas" (SEEGER, 1980, p. 126). Os Kisêdjê não estariam preocupados com seus ancestrais, possuindo formas de descendências fracas. "Muito da chamada amorfia da organização social [das TBAS] pode ser o resultado de buscarmos nos lugares errados os conceitos que organizam os grupos sociais" (SEEGER, 1980, p. 131).

O capítulo 7, Ponto de vista sobre os índios brasileiros: um ensaio bibliográfico, coescrito por Eduardo Viveiros de Castro, foi destinado a estudantes que estavam iniciando seus estudos sobre povos indígenas e para pesquisadores de outras áreas. Seeger reconhece que qualquer tentativa de abordar criticamente toda a literatura sobre as sociedades indígenas exigiria bem mais que um volume.

O autor trabalha diversas características da bibliografia ora existente sobre os povos indígenas, como o estado e os índios, a Igreja e os índios, antropólogos e índios, materialismo cultural, organização social, religião e cosmologia e contato e mudança social.

"Não existe um só "índio brasileiro" [...] mas muitos grupos diferentes de índios [...]" (SEEGER, 1980, p. 140), uma pontuação aparentemente ingênua, mas que, nos dias atuais, precisa cada vez mais ser dita na sociedade brasileira.

Mais uma vez o autor chama atenção para a música ao dizer da importância desta na vida cerimonial dos indígenas, mas que tem sido frequentemente esquecida. Só há pouco, dizia Seeger, em 1980, a Etnomusicologia tem sido levada a sério.

Seeger chama a atenção dos antropólogos ao dizer que estes não 
devem estar acomodados no academicismo, mas que o conhecimento deve estar vinculado à ação, e para nós tal vínculo deve acontecer em mão dupla e em constante movimento.

O capítulo e o livro encerram-se com o que poderia ser um imperativo: deve-se trabalhar da melhor forma para dar voz àqueles que foram durante séculos silenciados, a saber, os índios.

\section{Referências bibliográficas}

SEEGER, Anthony. Os índios e nós: estudos sobre sociedades tribais brasileiras. Rio de Janeiro: Campus, 1980.

Why Suyá sing: a musical anthropology of an Amazonian people. Urbana/Chicago: University of Illinois Press, 2004 [1987].

Por que cantam os Kisêdjê: uma antropologia musical de um povo amazônico. São Paulo: Cosac Naify, 2015.

Recebido em: 22/07/2016 * Aprovado em: 13/09/2016 * Publicado em: 31/12/2016 